\title{
PEMAHAMAN DASAR FILM DOKUMENTER TELEVISI
}

\author{
Dilmai Putra', Muhsin Ilhaq \\ Prodi Desain Komunikasi Visual (DKV) Politeknik Palcomtech \\ Prodi Seni Pertunjukan Univ. PGRI Palembang \\ Jl. Basuki Rahmat No. 5 Palembang \\ Jl. Jend. A. Yani. Lrg. Gotong Royong 9/10 Ulu Palembang
}

(dilmaiputra@palcomtech.ac.id, ilhaque@gmail.com )

\begin{abstract}
This paper describes the understanding of the basic elements of making documentary films, as a form of communication media that represents real life delivered through electronic media in the form of audio visuals such as television. The discussion in this paper describes the style and form of the documentary based on Gerzon Ayawaila's opinion written in the Documentary book from idea to production. In addition, it is necessary to consider visual elements in the process of realizing the documentary film, namely videography techniques and editing techniques. Television as a medium of conveying messages in which there is a power that presents the fact that the media can shape what we know about the world and can be the main source of various opinions and ideas. The achievement of maximum results is carried out through a systematic and planned process, so that it will get the form of a quality television program that can provide entertainment and knowledge to the audience.
\end{abstract}

Keywords: Documentary, Media, television program

ABSTRAK

Tulisan ini memaparkan tentang pemahaman unsur dasar penggarapan film dokumenter, sebagai salah satu bentuk media komunikasi yang merepresentasikan kehidupan nyata disampaikan melalui media elektronik berupa audio visual seperti televisi. Pembahasan pada tulisan ini menjelaskan gaya dan bentuk dokumenter berdasarkan pendapat Gerzon Ayawaila yang ditulis dalam buku Dokumenter dari ide sampai produksi. Selain itu, perlunya mempertimbangkan elemen-elemen visual dalam proses perwujudan film dokumenter yakni teknik videografi maupun teknik editing. Televisi sebagai sebuah media penyampai pesan dimana di dalamnya terdapat kekuatan yang menyajikan fakta bahwa media dapat membentuk apa yang kita ketahui tentang dunia dan dapat menjadi sumber utama berbagai opini dan ide. Pencapaian hasil yang maksimal dilakukan melalui proses sistematis dan terencana, sehingga akan mendapatkan wujud program televisi yang berkualitas yang dapat memberikan hiburan serta ilmu pengetahuan kepada audiensnya.

Kata Kunci : Dokumenter, Media, program televisi 


\section{Pendahuluan}

Media merupakan sebuah bentuk penyajian baik elektronik maupun cetak. Media elektronik merupakan bentuk media penyampaian informasi dengan menampilkan gambar bergerak disertai suara sedangkan media cetak menyampaikan informasi menggunakan gambar dan tulisan. Kejeniusan Thomas Alva Edison dan Lumiere bersaudara akhir abad ke 19 merupakan sebuah bukti nyata ketika sebuah gambar bergerak tercipta. Televisi merupakan sebuah media elektronik yang menampilkan suara dan gambar bergerak. Berbagai jenis tayangan televisi mulai dari berita, talks show, kuis dan film diproduksi secara beruntun.

Dari sekian banyak tayangan televisi diantaranya yaitu Film. Mengutip salah satu essai yang ditulis Goemawan Muhamad bahwasanya gambar hidup adalah keajaiban yang tak Cuma dilahirkan oleh teknologi tapi oleh kepandaian bercerita sehingga film menjadi sebuah media bertutur/sebuah alat komunikasi. Berbicara film kita akan dihadapkan kepada dua pilihan yaitu:

1. Fiksi (khayalan)

Merupakan sebuah cerita yang dibuat berdasarkan imajinasi creator.

2. Non fiksi (kenyataan)

Merupakan sebuah cerita berdasarkan kenyataan tanpa adanya unsur imajinasi yang membangun struktur ceritanya.

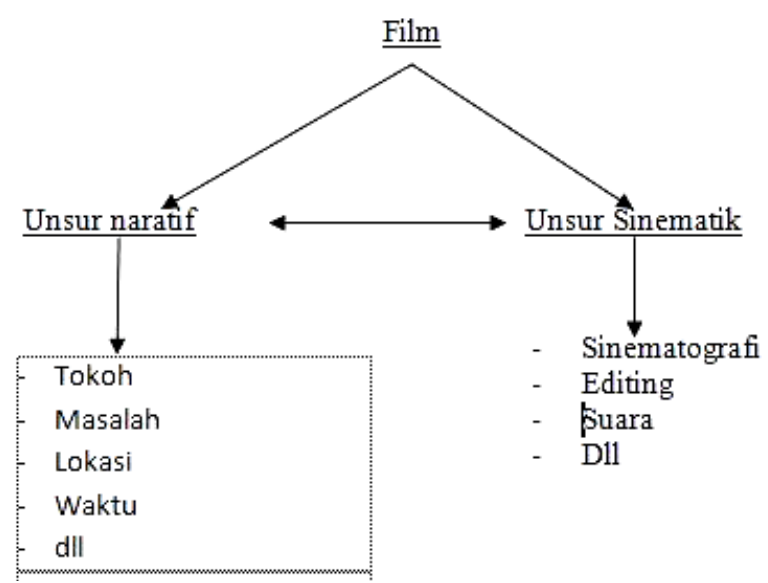

Secara garis besar ada dua unsur pembentuk film yaitu:

1. Unsur Naratif

Yaitu berhubungan dengan aspek cerita atau tema. Unsur yang membentuknya yaitu, tokoh, masalah, lokasi, waktu dan lain-lain.

2. Unsur Sinemantik

Yaitu sesuatu hal yang berhubungan dengan aspek teknis seperti Mise en scene, editing, suara, dan lain-lain.

Film merupakan sebuah cerita yang dicitrakan perihal kehidupan, atau merepresentasikan dunia nyata. Film memiliki kemampuan untuk menirukan sebuah kenyataan sedekat mungkin dengan kenyataan seharihari. Biasanya representasi dimulai dari sebuah proses melihat keadaan suatu kelompok masyarakat, kemudian dilanjutkan dengan merekonstruksikan kejadian kedalam sebuah scenario sampai film selesai dibuat. Namun realitas dalam sebuah film bukanlah realitas sebenarnya melainkan hanya sebagai imitasi kehidupan nyata.

Media visual tidak bisa dilepaskan dari unsur modalitas. Suatu media visual dapat dikategorikan realisitis atau tidak realistis berdasarkan unsur modalitasnya. Realisme dalam media visual dapat dikorespondensikan dengan kebenaran (truth) pada kode-kode verbal. Jadi, representasi dari suatu media visual (salah satunya film yang ditayangkan lewat media televisi) dapat dianggap sebagai suatu yang benar apabila yang disajikannya sesuatu yang realisitis. Penikmat akan menjauh dari suatu media visual bila dianggap tidak realistis. Dalam suatu tampilan, aspek modalitas dapat dilihat dari mimetik plane. Sebuah media visual seperti karikatur akan realistis bila representasi realitasnya sesuai dengan keadaan yang sebenarnya.

Penanda modalitas diinterpretasi sebagai suatu kompleks makna dalam suatu rangkaian modalitas. Pengamatan terhadap modalitas terletak pada acuannya pada model semiosis normatif yang di dalamnya terdapat produser dan pesan serta representasi realita.

\section{Pembahasan}

Informasi yang disampaikan lewat media televisi yang ditangkap langsung melalui indera mata penontonnya sebagian merupakan informasi yang kongkrit, sehingga didapatkan informasi yang cukup jelas, baik warna, bentuk serta ukurannya, karena itu televisi merupakan suatu alat yang mampu mengkomunikasikan suatu gagasan atau informasi. Televisi merupakan media yang memberikan informasi terbesar bila dibandingkan dengan media penyampai informasi lainnya. Darwanto Sastro Subroto dalam bukunya Produksi Acara Televisi menjelaskan (1998:15); "Sesuai dengan cara menyampaikan pesan informasinya, televisi sebagai media massa seperti halnya radio dimana proses komunikasinya hanya berjalan satu arah saja (one way communication), artinya si penerima pesan (komunikan) tidak dapat berhubungan langsung dengan pengirim pesan (komunikator), demikian pula komunikatornya pada media televisi tidak bersifat individual melainkan bersifat kolektif, sedang massa komunikannya adalah para penontonnya yang mempunyai karakteristik tersendiri”.

Televisi memerlukan program-program dalam penayangannya agar selalu dinikmati oleh penikmatnya. Suatu kejadian yang istimewa biasanya merupakan materi produksi yang baik untuk program-program televisi. Untuk menjadikan program-program itu sebuah 
program yang utuh diperlukan riset yang mendalam agar semua data yang berkaitan dengan program tersebut menjadi utuh, semakin dalam hasil riset yang dilakukan maka akan semakin lengkap pula data-data yang didapat yang kemudian diolah menjadi sebuah program televisi.

Salah satu jenis program televisi adalah dokumenter. Dokumenter merupakan jenis program televisi non fiksi, secara sederhana film dokumenter merupakan film yang menampilkan fakta yang ada dalam kehidupan atau film yang menampilkan tentang kenyataan.

Hal senada juga diperjelas oleh Fred Wibowo (1997:96): “dokumenter adalah program yang menyajikan suatu kenyataan berdasarkan pada fakta objektif yang memiliki nilai esensial dan eksistensial, artinya menyangkut kehidupan, lingkungan hidup dan situasi yang nyata". Di dalam beberapa literatur disebutkan bahwa istilah documentary atau documenter pertama digunakan oleh John Grierson tahun 1926 (Gerzon Ayawaila,2008:11).

Film dokumenter merupakan salah satu jenis film yang sering digunakan televisi dalam mengisi program siarannya. Program dokumenter dalam tayangan televisi merupakan perkembangan dari format program jurnalistik yang terdiri dalam lima kategori yaitu: esai berita aktual, feature, magazine, dokumenter televisi, dan dokumenter seri televisi. (Gerzon Ayawaila, Dokumenter dari ide Sampai Produksi, 2008:26).

Selain itu film dokumenter juga bisa menjadi pilihan yang cocok untuk dijadikan sumber belajar oleh guru di sekolah bagi siswa- siswanya. Karena film dokumenter merupakan penuturan fakta-fakta yang sebenarnya sehingga tidak ada perekayasaan dalam produksinya. Film dokumenter yang dijadikan dalam proses pembelajaran adalah film-film yang mengangkat tema kebudayaan baik adat istiadat maupun keseniankesenian daerah dan juga tema yang berkaitan dengan keilmuan, apapun bidang keilmuannya seperti biologi, sejarah, fisika dan lainnya selagi pemaparan dalam film dokumenternya memberi pengetahuan yang positif kepada penontonnya.(Riki Rikarno, Jurnal Ekspresi Seni, vol. 7 no.1. 2015).

Konsep film faktual dan film dokumentasi yang berkolaborasi menghasilkan suatu karya film dokumenter atau di program televisi disebut sebagai dokumenter televisi. Film dokumenter marak dibuat dan telah menjadi industri film sendiri yang berkembang pesat di dunia. Film dokumenter berkembang pesat seiring dengan kemajuan teknologi permasalahan yang lebih kompleks dalam kehidupan manusia secara regional maupun internasional. (Arie Atwa Magriyanti, Jurnal Ilmiah Komputer Grafis vol. 13, No 2.2020).

Dokumenter televisi merupakan salah satu bentuk format program televisi, yang temasuk kedalam program film non fiksi. Menurut Gerzon Ayawaila dalam bukunya Dokumenter dari ide Sampai Produksi (2008:35) bahwa: "Dokumenter merupakan sesuatu kenyataan yang divisualisasikan ke dalam bentuk audio visual tanpa ada rekayasa, bisa berisi kupasan mengenai suatu peristiwa, suatu kejadian, suatu riwayat hidup bahkan suatu prakondisi yang bisa menimbulkan kejadian tertentu". Gerzon Ayawaila dalam bukunya Dokumenter dari ide sampai produksi juga menjelaskan beberapa gaya dan bentuk dalam dokumenter, diantaranya:

\section{a) Laporan perjalanan}

Merupakan bentuk dokumenter dengan ide awalnya adalah catatan perjalanan, bentuk ini juga dikenal dengan nama travel film, travel documentary, adventure film, dan road movie. Bentuk film dokumenter ini pertama kali dibuat oleh Cherry Kearton yang berjudul In Seville (1909), yang mengisahkan ekspedisi penelitian ke Alaska dan Siberia.

b) Sejarah

Merupakan bentuk documenter yang awal munculnya dimaksudkan untuk propaganda. Diawali saat meletusnya perang dunia I sekitar tahun 1914 hingga 1918, kemudian dilanjutkan pada perang dunia II sekitar tahun 1935 hingga 1950-an. Waktu itu film lebih diposisikan untuk kebutuhan propaganda. Bentuk dokumenter ini biasanya memiliki durasi yang sangat panjang.

c) Potret atau Biografi

Film documenter jenis ini merupakan representasi kisah pengalaman hidup seorang tokoh terkenal ataupun anggota masyarakat biasa yang riwayat hidupnya dianggap hebat, menarik, unik, atau menyedihkan. Bentuk potret umumnya berkaitan dengan aspek human interest, sementara isi tuturan biasa merupakan kritikan, penghormatan, atau simpati. Potret tidak harus mengenai seseorang atau individu, tetapi dapat pula mengenai sebuah komunitas, sekelompok kecil individu, atau sebuah lokasi.

d) Perbandingan

Dokumenter ini merupakan bentuk dokumenter yang mengetengahkan perbedaan suatu situasi atau kondisi, dari satu objek/sabjek dengan yang lainnya. Biasanya dokumenter ini dikemas kedalam bentuk dan tema yang bervariasi, selain itu dapat pula digabungkan dengan bentuk penuturan lainnya untuk mengetengahkan suatu perbandingan.

e) Kontradisi

Dari sisi bentuk atau isi, tipe kontradisi memiliki kemiripan dengan tipe perbandingan, hanya saja tipe kontradisi cenderung lebih kritis dan radikal dalam mengupas permasalahan. Perbedaan yang sangat mencolok adalah: tipe perbandingan hanya memberikan alternatif-altenatif saja, sedangkan tipe kontradisi lebih menekankan pada visi dan solusi mengenai proses menuju suatu inovasi.

f) Ilmu Pengetahuan 
Bentuk dokumenter ini berisi penyampaian informasi mengenai suatu teori, system, berdasarkan disiplin ilmu tertentu. Jenis ini biasanya dibuat untuk keperluan lembaga pendidikan formal ataupun non formal.

g) Nostalgia

Kisah yang kerap diangkat dalam documenter nostalgia adalah kisah kilas-balik atau napak tilas para veteran perang Amerika yang kembali mengunjungi Vietnam atau Kamboja. Biasanya - dalam bahasa inggris judul dokumenter tipe ini diawali dengan tulisan "Back to..." Contoh nya : Back to Saigon karya Anthony Grey.

h) Rekonstruksi

Pada umumnya bentuk dari documenter ini dapat ditemui pada documenter investigasi dan sejarah, termasuk pula pada film etnografi dan antropologi Visual. Dalam tipe ini, pecahan-pecahan atau bagian-bagian peristiwa masa lampau maupun masa kini disusun atau direkonstruksi berdasarkan fakta sejarah.

i) association picture story

Disebut juga sebagai film eksperimen atau film seni. Unsur utama dalam dokumenter ini adalah gabungan gambar, musik dan suara (noise). Biasanya dokumenter ini tidak pernah menggunakan narasi, komentar, maupun dialog.

j) Investigasi

Istilah ini muncul pertama kali dari Nellie Bly (aslinya perempuan ini bernama Elizabeth Jane Cochran) ketika dia menjadi reporter di surat kabar Pittsburgh Dispatch, tahun 1890. Ketika itu, Bly sedang menyelidiki kasus buruh anak yang dipekerjakan dalam kondisi yang memprihatinkan. Tipe ini disebut juga dengan investigative journalism, karena metode kerjanya dianggap berkaitan erat dengan jurnalistik. Biasanya dokumenter ini mencoba untuk mengungkap misteri-misteri dari sebuah peristiwa yang belum atau tidak pernah terungkap dengan jelas.

k) Buku Harian

Penuturan yang subjektif pada bentuk dokumenter ini terasa sangat jelas karena sifat dari buku harian yang sangat pribadi. Penuturannya sama seperti catatan pengalaman hidup sehari-hari dalam buku harian pribadi.

1) Dokudrama

Merupakan bentuk dan gaya bertutur yang memiliki motivasi komersial. Karena itu subjek yang berperan disini adalah artis film. Biasanya menampilkan profil suatu produk atau profil sebuah perusahaan untuk kepentingan promosi.

Dalam mengamati sebuah film, latar sejarah dapat ditelusuri dari aspek modalitas seperti model gambar, gender dari model pakaian, bahasa dan lainnya.
Modalitas pada genres media visual seperti film, mempunyai jaringan yang kompleks dan cukup rumit untuk diamati. Sehubungan dengan modalitas pada media visual, beberapa hal dapat disimpulkan sebagai berikut.

1. Berbagai fitur teks visual yang merupakan signifier yang transparan dari aktivitas semiotik (hubungan antara produser dan penerima teks, teks dan referen) bertindak sebagai isyarat modalitas, menandai status teks atau bagian teks apakah mempunyai afinitas tinggi atau tidak.

2. Teks visual mengimplikasikan isi yang bersifat mimetik yang berisi nilai modalitas berdasarkan afinitas pengalaman pihak yang menilai kemodalitasan sebuah teks. Nilai modalitas tergantung pada orieantasi dan posisi penerima pesan.

3. Karena signifier dari modalitas dikonstruksikan dari kategori ideologis semiosis dan mimetic plane, modalitas dan ideologis dapat berinteraksi. Ideologi memunculkan nilai modalitas dan modalitas melegitimasi nilai ideologis. Penolakan nilai ideologis teks atau genre mengharuskan reklasifikasi secara drastis aspek modalitasnya.

4. Genre yang berbeda, apakah diklasifikasikan berdasarkan medium (komik, kartun, film, TV, lukisan dll) atau berdasarkan isi (bersifat kebaratan, science fiction, berita dan lain-lain) memiliki seperangkat penanda modalitas khusus, yang sekaligus berfungsi sebagai baseline masing-masing genre itu. Base-line itu akan berbeda bagi pembaca, pengamat yang berbeda dan teks serta momen yang berbeda.

Berangkat dari uraian di atas, maka perwujudan media audio visual, perlu kiranya dilakukan hal yang mengandung unsur entertain yaitu:

1. Videografi untuk mewujudkan sajian audio visual dengan bentuk dokumenter dapat menggunakan teori komposisi dalam penataan videografi. Teori komposisi adalah proses menggabungkan dan mengatur elemen-elemen visual sehingga menjadikan satu kesatuan gambar yang memiliki makna yang baru (Peter ward, 2003:10).

Elemen-elemen dasar yang terdapat pada gambar, yaitu; tipe shot, angle, movement, optical lens, framing, dan warna. Roy Thompson membagi element gambar atau element of the shot (1998:27) seperti bagan di bawah ini: 
Scene

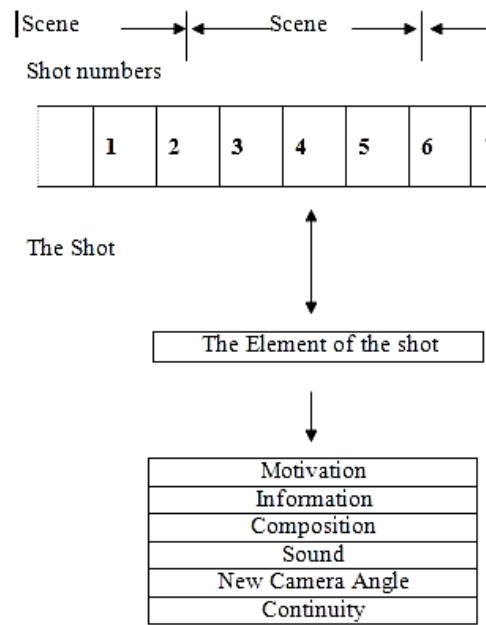

Gambar 1.Skema Element of the Shot

Elemen elemen visual yang dapat digunakan dalam proses perwujudan film dokumenter diantaranya:

a. Teknik videografi,

Ukuran shot

- Extreme Close-up (ECU)

Merupakan ukuran shot dengan menampilkan kedetilan suatu objek. contoh: mata saja atau hidung saja. Kekuatan Extreme Close-up adalah pada kedekatan dan ketajaman yang hanya fokus pada satu objek.

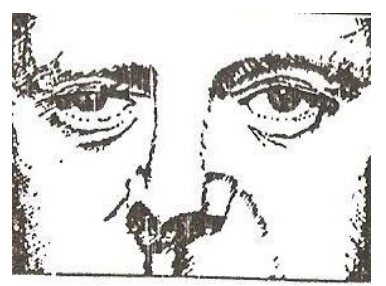

Gambar 2. ECU

- Close-Up (CU)

Merupakan ukuran shot dari leher hingga ke ujung batas kepala. CU juga bisa diartikan sebagai komposisi gambar yang "fokus kepada wajah" maka CU seringkali menjadi bagian dari ungkapan dari emosi dari objek utama.

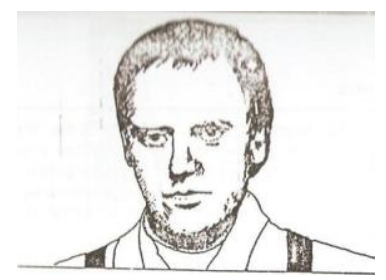

Gambar 3. CU

- Medium close-up (MCU)

Merupakan ukuran shot dari perut hingga atas kepala dengan view background masih cukup jelas. Pada MCU, karakter gambar lebih menunjukkan profil dari objek yang direkam.

Gambar 4. MCU

- Long shot

Merupakan ukuran shot dari lutut hingga ujung kepala, MLS juga dikenal dengan Knee Shot.

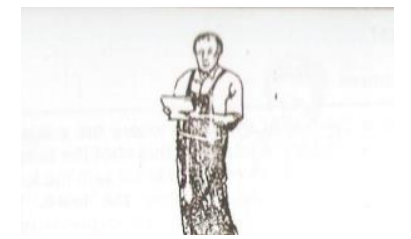

Gambar 5. LS

- Group shot

Merupakan ukuran shot dengan jumlah objek lebih dari 2. Group shot umumnya dipadukan dengan ukuran shot yang lebar lainnya.

b. Teknik Editing

Editing merupakan proses pemotongan dan penyambungan gambar hasil dari proses syuting di lapangan sehingga menjadi gambar utuh yang bisa dinikmati sesuai dengan alur/cerita yang telah dibuat sebelumnya. Secara umum konsep editing yang digunakan ialah $\mathrm{Cut}$ to $\mathrm{Cut}$ dan Optical effect.

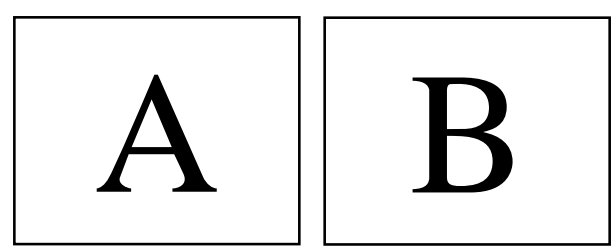

Gambar 6. Skema Cut to Cut

Cut to cut merupakan sebuah jenis transisi shot ke shot lainya secara langsung. Dalam film jenis apapun, bentuk editing ini adalah yang paling umum digunakan. Cut sifatnya sangat fleksibel hingga memungkinkan untuk editing kontinu maupun diskontinu. Sedangkan Optical effect adalah perpindahan gambar dengan menggunakan efek khusus seperti dissolve, fade dan wipe. Umumnya optical effect digunakan untuk editing diskontinu.

Editing diskontinu paling sering digunakan pada adegan yang terjadi pada ruang yang sama seperti adegan dialog, dapat pula digunakan 
pada ruang atau lokasi yang berbeda untuk menghubungkan beberapa aktivitas yang saling berhubungan langsung (Himawan Pratista, 2008:131).

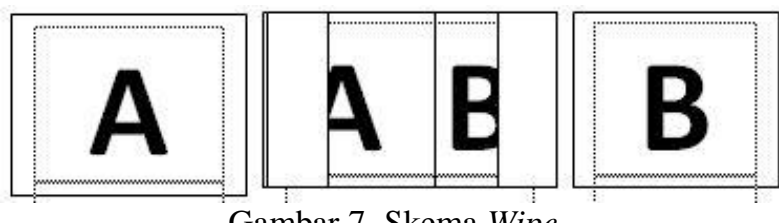

Wipe merupakan transisi shot dimana frame sebuah shot bergeser ke arah kiri, kanan, atas, bawah, atau lainnya hingga berganti menjadi sebuah shot baru.

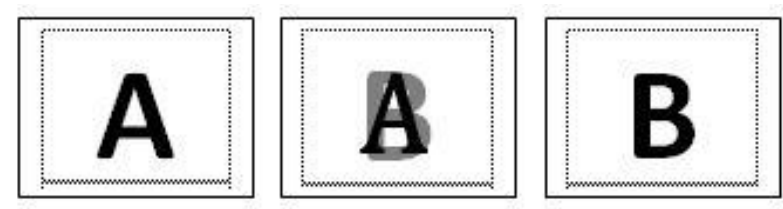

Gambar 8. Skema Dissolve

Dissolve merupakan transisi shot dimana gambar pada shot sebelumnya (A) selama sesaat bertumpuk dengan shot setelahnya (B). Dissolve ini digunakan ketika perpindahan gambar dengan bumper in dan bumper out.
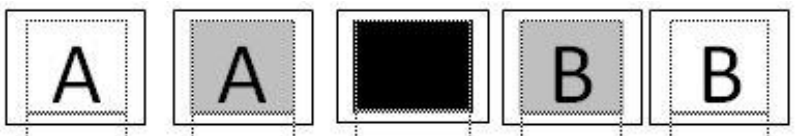

Gambar 9. Skema Fade

Fade merupakan transisi shot secara bertahap dimana gambar secara perlahan intensitasnya bertambah gelap hingga seluruh frame berwarna hitam dan ketika gambar muncul kembali bertambah terang. Fade terbagi dua, fade in dan fade out.

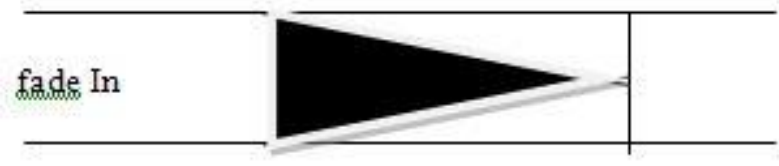

gambar 10. Skema Fade In

fade in digunakan ketika awal munculnya gambar di layar. Pertama-tama layar gelap, secara perlahan intensitasnya bertambah terang dan gambar awal mulai kelihatan.

Gambar 11. Skema Fade Out

fade out digunakan untuk mengakhiri gambar dilayar, atau menutup film.

\section{Kesimpulan}

Televisi sebagai sebuah media penyampai pesan dimana di dalamnya terdapat kekuatan yang menyajikan fakta bahwa media dapat membentuk apa yang kita ketahui tentang dunia dan dapat menjadi sumber utama berbagai opini dan ide. Pencapaian hasil yang maksimal dilakukan melalui proses sistematis dan terencana, sehingga akan mendapatkan wujud program televisi yang berkualitas. Kehadiran sebuah program televisi melalui suatu proses cipta jarang sekali lahir secara tiba-tiba, akan tetapi sudah terencana secara matang, baik menyangkut ide, bentuk, bahan, teknik, makna, dan simbol yang ingin disampaikan, sehingga hasil akhirnya dalam bentuk sajian program televisi dapat dinikmati oleh khalayak dan tujuan dari program itu dapat tercapai dengan maksimal melalui karya seni yang diciptakan.

Dokumenter merupakan karya film berdasarkan realita dan fakta dari suatu pengalaman hidup seseorang atau sebuah peristiwa sejarah. Maka realita, kepekaan terhadap lingkungan sosial, budaya, politik dan alam semesta, disertai rasa ingin tahu yang besar dengan membaca, berkomunikasi antar manusia dalam pergaulan, merupakan sumber inspirasi yang besar dalam karya film dokumenter.

Ide cerita untuk film dokumenter bukan berdasarkan khayalan yang sifatnya imajinatif. Ide tema bagi dokumenter hanya dapat diperoleh dari apa yang dilihat dan didengar. Dalam hal ini, banyak mengamati lingkungan, berkomunikasi dengan orang yang dianggap kompeten.

\section{Daftar Pustaka}

Ayawaila, Gerzon. R, (2012). Dokumenter: Dari Ide sampai Produksi, FFTV IKJ Press, Jakarta.

Arie Atwa Magriyanti, Hendri Rasminto, Film

Dokumenter Sebagai Media Informasi Kompetensi

Keahlian SMK Negeri 11 Semarang. Jurnal Ilmiah

Komputer Grafis 13 (2):123-132

Pratista, Himawan. (2010). Memahami Film, Homerian Pustaka, Yogyakarta.

Riki Rikarno, Film Dokumenter sebagai sumber belajar siswa. Jurnal Ekspresi Seni 17(1): 129-149. 